\title{
S/MAR-binding properties of Sox2 and its involvement in apoptosis of human NT2 neural precursors
}

\author{
JX Lei ${ }^{1}$, QY Liu ${ }^{*, 1}$, C Sodja ${ }^{1}$, J LeBlanc ${ }^{1}$, M Ribecco-Lutkiewicz ${ }^{1}$, \\ B Smith ${ }^{1}$, C Charlebois ${ }^{1}$, PR Walker ${ }^{1}$ and M Sikorska ${ }^{*, 1}$ \\ ${ }^{1}$ Neurobiology Program, Institute for Biological Sciences, National Research \\ Council of Canada, Ottawa, Ontario, Canada K1A OR6 \\ * Corresponding author: M Sikorska or Q Liu, Neurobiology Program, Institute \\ for Biological Sciences, National Research Council of Canada, 1200 Montreal \\ Rd., Bldg. M-54, Ottawa, Ontario, Canada K1A OR6. \\ Tel.: + 16139900850 or + 1613993 5916; Fax: + 16139907963 ; \\ E-mail: marianna.sikorska@nrc.ca, qing_yan.liu@nrc.gc.ca
}

Received 10.12.04; revised 16.3.05; accepted 18.4.05; published online 27.5.05 Edited by B Zhivotovsky

\begin{abstract}
DNA fragmentation in apoptosis, especially in lymphocytic cells, is initiated at scaffold/matrix attachment regions (S/ MARs) and is preceded by the degradation of nuclear proteins. The present study was performed to establish whether the same mechanism occurred in human NT2 cells subjected to oxygen and glucose deprivation (OGD). We analyzed the integrity of c-myc S/MAR containing a baseunpairing region (BUR)-like element, which we established to be a binding site of the transcription factor Sox2. An accumulation of DNA breaks in close proximity to this element and a degradation of Sox2 were observed early in the OGD-induced apoptotic response. Identification of Sox2 as a novel c-myc BUR-binding protein was achieved through yeast one-hybrid screening and the Sox2/DNA interaction was confirmed by electrophoretic mobility shift assay and immunoprecipitation with Sox2 antibody. Our data support the notion that early proteolysis of unique BUR-binding proteins might represent a universal mechanism that renders these DNA sites vulnerable to endonucleolysis.

Cell Death and Differentiation (2005) 12, 1368-1377.

doi:10.1038/sj.cdd.4401671; published online 27 May 2005
\end{abstract}

Keywords: nuclear matrix; DNA breaks; proteolysis; LM-PCR; yeast one-hybrid screening

\section{Introduction}

DNA degradation and its associated chromatin collapse have been extensively studied over the years and are regarded as the classical hallmarks of apoptosis. ${ }^{1,2}$ The actual DNA cleavage steps are well defined, although the molecular mechanisms involved in the initiation of this process are not fully understood and are controversial. Several studies strongly suggest that proteolytic degradation of key components of the nuclear matrix, leading to the exposure of vulnerable chromatin sites to an endonucleolytic attack, plays a fundamental role in apoptotic nuclear disassembly. ${ }^{3-6}$
In the eukaryotic nucleus, chromosomes are organized into three-dimensional structures that involve the attachment of DNA loops to the nuclear matrix scaffold. The contact region of the DNA loop with the nuclear matrix is at the base of the loop and is referred to as scaffold/matrix attachment regions $\left(\mathrm{S} / \mathrm{MARs}^{7}\right)$. The mean length of S/MARs is approximately $2 \mathrm{~kb}^{8}$ and each S/MAR sequence contains a short element of 150$200 \mathrm{bp}$, which, under negative superhelical strain, potentiates the unwinding of DNA strands, thus called a base-unpairing region (BUR) ${ }^{9,10} \mathrm{~S} / \mathrm{MARs}$ can be found throughout the genome and are often located at the boundaries of transcription units near enhancer regions or within origins of DNA replication.

A number of MAR-binding proteins have been identified, including topoisomerase II, lamin A/B, SATB1, SAF-A, PARP, the Ku subunit of DNA-PK, Bright and HMG-I(Y). ${ }^{11-15}$ Most of them are components of the nuclear matrix and several have been shown to undergo site-specific proteolysis in the early stage of apoptosis. . $^{3,16,17}$ Consequently, this process has been temporally linked to the initiation of DNA cleavage, suggesting that the latter may be a consequence of the loss of the proteinacious insulation. ${ }^{3,6}$ Recently, we have provided direct evidence that the integrity of genomic DNA in the vicinity of BUR-like elements of several genes is profoundly affected in Jurkat cells undergoing anti-Fas-induced apoptosis. ${ }^{6}$ These BUR sites are highly similar to a 25 bp core BUR element of the IgH gene, a known binding site of SATB1 protein. ${ }^{11}$ Indeed, preferential accumulation of multiple ssDNA breaks occurs in close proximity to these sites, concomitant with site-specific proteolysis of BUR-binding SATB1 protein. This is consistent with the model, in which degradation of MAR-binding proteins permits the accumulation of DNA breaks and the initiation of apoptotic disassembly of nuclear chromatin. However, the question still remains whether this process occurs only in lymphocytic cells, such as Jurkat, or whether it represents a universal feature of apoptosis.

To address this question, we examined the integrity of the S/MAR region of the c-myc proto-oncogene, located within the $3^{\prime}$ UTR, ${ }^{18,19}$ in human NT2 embryonal carcinoma cells undergoing apoptosis in response to oxygen and glucose deprivation (OGD). The c-myc S/MAR sequence also contains a 22 bp BUR-like core element, a putative protein-binding site. ${ }^{6}$ We used four tandem copies of this element as bait for a yeast one-hybrid screen of a human fetal brain cDNA expression library and identified a brain-specific transcription factor Sox2, known for its role in the development of $\mathrm{CNS},{ }^{20-23}$ as a novel c-myc MAR-binding protein. Following induction of apoptosis, Sox2 underwent site-specific proteolysis and the c-myc S/MAR extensive endonucleolysis.

\section{Results}

\section{Identification of c-myc S/MAR region}

We applied the SMARTest module of the GenomatixSuite software package ${ }^{8,24}$ (Genomatix Software $\mathrm{GmbH}$, München, 
Germany) to inspect the genomic sequence of the $c$-myc gene (acc. \# X00364, UCSC Human genome version hg16) obtained via the UCSC Genome Browser. ${ }^{25}$ The analysis confirmed the presence of a $370 \mathrm{bp}$ S/MAR region located in the $3^{\prime}$ UTR between nt 7366-7735, consistent with previous studies of Chou et al., ${ }^{18,19}$ who reported the presence of a MAR at the $3^{\prime}$-end of the gene within a $1.4 \mathrm{~kb}$ Clal and EcoRI restriction fragment (Figure 1). Furthermore, within this $370 \mathrm{bp}$ S/MAR region, we identified a sequence (5'TTTTTTTCTA TTGTTTTTAGAA3', nt 7627-7647) highly homologous to the well-characterized $25 \mathrm{bp}$ BUR core element of the mouse IgH gene.,11 Subsequently, we proceeded to establish whether this segment of the $c-m y c$ gene was attached to the nuclear matrix (Figure 2). Isolated matrix preparations from Jurkat (Figure 2a) and NT2 (Figure 2b) cells were double digested with restriction enzymes Hincll and Sacl to remove unattached DNA sequences. DNA was extracted and PCR was performed using primers amplifying a 298 bp fragment spanning the putative BUR-like core region and a $483 \mathrm{bp}$ fragment located $1209 \mathrm{bp}$ away from the $22 \mathrm{bp}$ AT-rich BUR-like element (Figure 1). The data showed that in both cell types only the $298 \mathrm{bp}$ fragment containing the BUR-like element (Figure $2 a$ and $b$, lane 2), but not the $483 \mathrm{bp}$ fragment outside the MAR (Figure $2 \mathrm{a}$ and $\mathrm{b}$, lane 1), was amplified from the nuclear matrix extracted DNA (Figure $2 a$ and $b$, left-hand panels). Both fragments were clearly amplified from the total genomic DNA template (Figure $2 \mathrm{a}$ and $\mathrm{b}$, right-hand panels), which was extracted and restriction digested in the same fashion as the matrixattached DNA pool.

\section{Detection of DNA breaks in the c-myc S/MAR sequence during apoptosis}

We examined the integrity of the c-myc S/MAR DNA in NT2 cells subjected to $17 \mathrm{~h}$ of OGD (Figure 3 ). This treatment triggered the cell death program, as evidenced by the subsequent loss of cell viability measured by trypan blue staining (Figure 3A). Within 3-4 h post-OGD, approximately $25-30 \%$ of cells were trypan blue positive and their number increased further to over $50 \%$ by $24 \mathrm{~h}$ post-treatment. The nuclear morphology of treated cells, that is, nuclear condensation and formation of apoptotic bodies, revealed after DNA staining with Hoechst dye was consistent with apoptosis (Figure 3B).
Genomic DNA was collected 3h post-OGD, extracted and analyzed by LM-PCR for the presence of DNA breaks in the proximity of the BUR site. As shown in Figure $3 \mathrm{C}$, multiple radiolabeled bands, each corresponding to one ss break, were detected in the OGD-treated sample (lane 2) as compared to the control genomic DNA (lane 1). The major bands, indicated by arrowheads, corresponded exactly to those detected in Jurkat cells undergoing anti-Fas-induced apoptosis. $^{6}$

\section{Identification of Sox2 as a c-myc S/MAR-binding protein}

Yeast one-hybrid screening of a human fetal brain cDNA library was performed using four tandem copies of c-myc BUR sequence (5'TTTTTTTCTATTGTTTTTAGAA3') as bait. From $3 \times 10^{6}$ transformants, only one clone displayed histidine prototrophy and $\beta$-galactosidase activity (Figure $4 \mathrm{a}$ and $b$, lane 3 ). This activation of the reporter gene was tested in parallel with a positive control (Figure $4 a$ and b, lane 1) and a negative control (Figure $4 a$ and $b$, lanes 2 and 4 ) under the same selection conditions. Sequence analysis and Genbank searches revealed that the clone contained a full-length cDNA of the human Sox2 gene fused in frame with the Gal4 activation domain in the pACT2 library vector.

Physical interaction of Sox 2 with the 22 bp c-myc BUR core sequence was confirmed using in vitro translated Sox2 protein. In the electrophoretic mobility shift assay (EMSA)
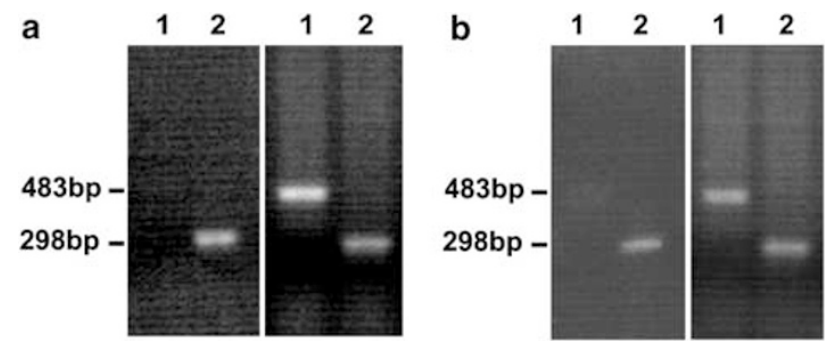

Figure 2 Presence of the c-myc MAR sequence in the isolated nuclear matrix. Nuclear matrix fractions from Jurkat (a) and NT2 (b) cells were isolated; DNA was extracted and double digested with restriction enzymes Hincll and Sacl, as described in Materials and methods. PCR reactions were performed using the nuclear matrix extracted DNA ( $\mathbf{a}$ and $\mathbf{b}$, left-hand panel) and total genomic DNA (a and $\mathbf{b}$, right-hand panels) as templates. (a, b) lane 1 - amplification of the $483 \mathrm{bp}$ fragment outside the MAR region, lane 2 - amplification of the $298 \mathrm{bp}$ fragment spanning the BUR element

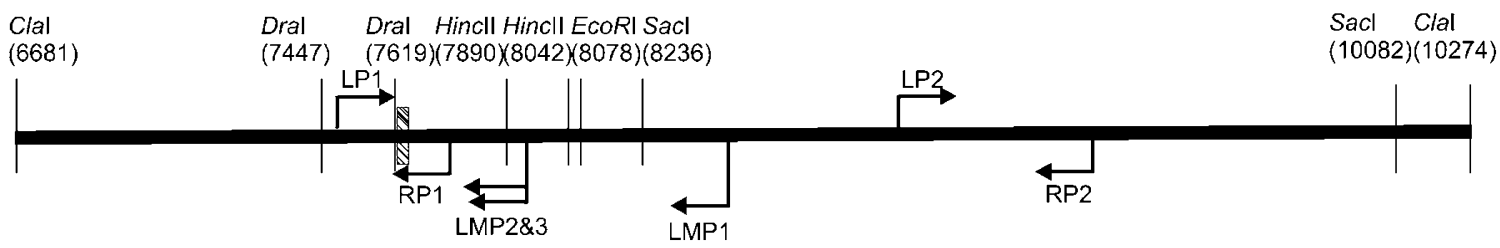

Figure 1 A Schematic representation of the c-myc gene Clal fragment. This fragment was derived from the latest Genbank version of the $c$-myc gene, with an accession number X00364. The diagram shows the relative position of the PCR and ligation-mediated PCR primers to the BUR region. Horizontal line - DNA strand; hatched box - core BUR sequence and a protein-binding site; arrows - primers and their directions of extension; vertical lines - positions of relevant restriction enzyme sites; LP1 - forward primer for the amplification of a 298 bp fragment containing the c-myc BUR core sequence; RP1 - reverse primer for the amplification of the $298 \mathrm{bp}$ fragment; LP2 - forward primer for the amplification of a 483 bp fragment outside the c-myc MAR sequence; RP2 - reverse primer for the amplification of the 483 bp fragment; LMP1 and LMP2\&3 - primers used for ligation-mediated PCR (listed in Table 1) 


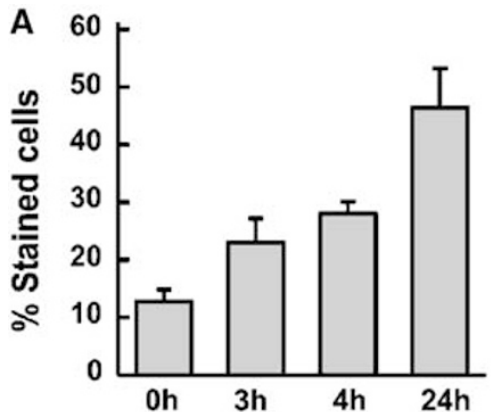

C

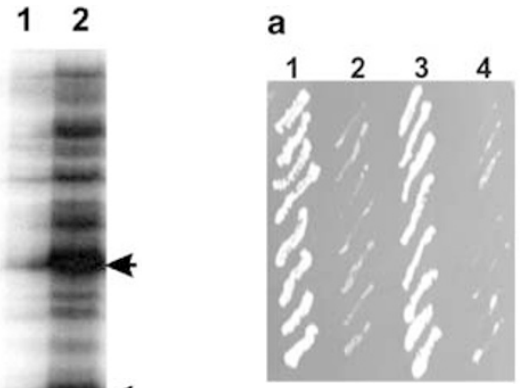

b

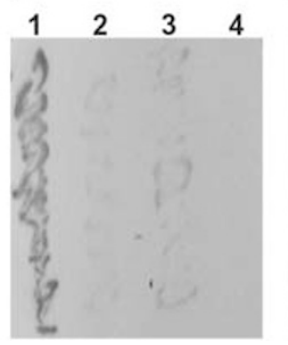

C

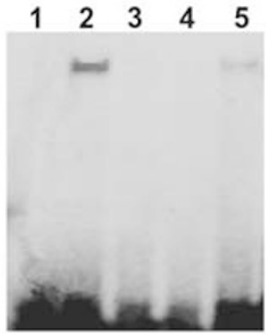

Figure 4 A yeast one-hybrid screen of a human brain CDNA library with the cmyc BUR sequence as bait. (a) The activation of His reporter gene on the SD/His-Leu + 45mM 3-AT selection plate. Lane 1 - positive control showing the interaction of p53 protein with its binding sequence in YM4271::p53:: his3 reporter strain, lane 2 - negative control of p53-binding sequence alone in YM4271:: p53:: his reporter strain, lane 3 - isolated positive clone showing the interaction of Sox2 protein with the c-myc BUR sequence in YM4271:: Myc:: His3 reporter strain, lane 4 - negative control of c-myc MAR sequence alone in YM4271:: Myc:: His3 reporter strain. (b) The activation of LacZ reporter gene (filter assay). Lane 1 - positive control showing the interaction of $p 53$ protein with its binding sequence in $Y M 4271:: p 53::$ LacZ reporter strain, lane 2 negative control of p53-binding sequence alone in YM4271:: p53:: LacZ reporter strain, lane 3 - isolated positive clone showing the interaction of Sox2 protein with c-myc MAR sequence in YM4271:: Myc:: lacZ reporter strain, lane 4 - negative control of c-myc MAR sequence alone in YM4271:: Myc:: lacZ reporter strain. (c) Interaction of in vitro translated Sox2 protein with the c-myc BUR in the EMSA assay. Lane 1 - the c-myc probe alone, lane 2 - Sox2 protein with the radiolabeled c-myc probe, lane 3 - Sox 2 protein with the c-myc probe and the presence of 100 -fold excess of cold oligonucleotides, lane 4 - negative control with an in vitro translated PKC- $\delta$ and the c-myc probe, lane $5-$ Sox2 protein with the mutated c-myc BUR sequence

indicated that Sox2 was capable of specific recognition and binding to the c-myc BUR element.

\section{In vivo interaction of SOX2 with the c-myc BUR core sequence}

We generated a rabbit polyclonal antibody raised against the human full-length Sox2 protein in order to study its interaction with the c-myc BUR core sequence in vivo. Using nuclear proteins extracted from undifferentiated NT2 cells and a radiolabeled c-myc BUR probe, we performed the EMSA assay to demonstrate the DNA-binding properties of endogenous Sox2 (Figure 5a). Two distinct bands, representing DNA/protein complexes, were seen under these conditions (lane 4), but only the gel mobility of the top band, but not the lower one, was the same as that obtained with in vitro translated Sox2 protein, which was used as reference (lane 1). Although both complexes became undetectable in the presence of 100-fold excess of unlabeled probe (lanes 2 and 5 ), again, only the mobility of the top band was supershifted by Sox2 antibody (lane 6), indicating the presence of Sox2 protein in this complex. The protein composition of the lower complex is at present unknown.

In order to establish the presence of Sox2 in the nuclear matrix fraction, we isolated both soluble and insoluble (matrix) nuclear proteins and analyzed them by Western blotting. As shown in Figure $5 \mathrm{~b}$, the $35 \mathrm{kDa}$ band of Sox 2 was present in both fractions, indicating that a portion of Sox2 was tightly associated with the insoluble nuclear matrix (lane 2). To further characterize these nuclear protein fractions, the blot 
a

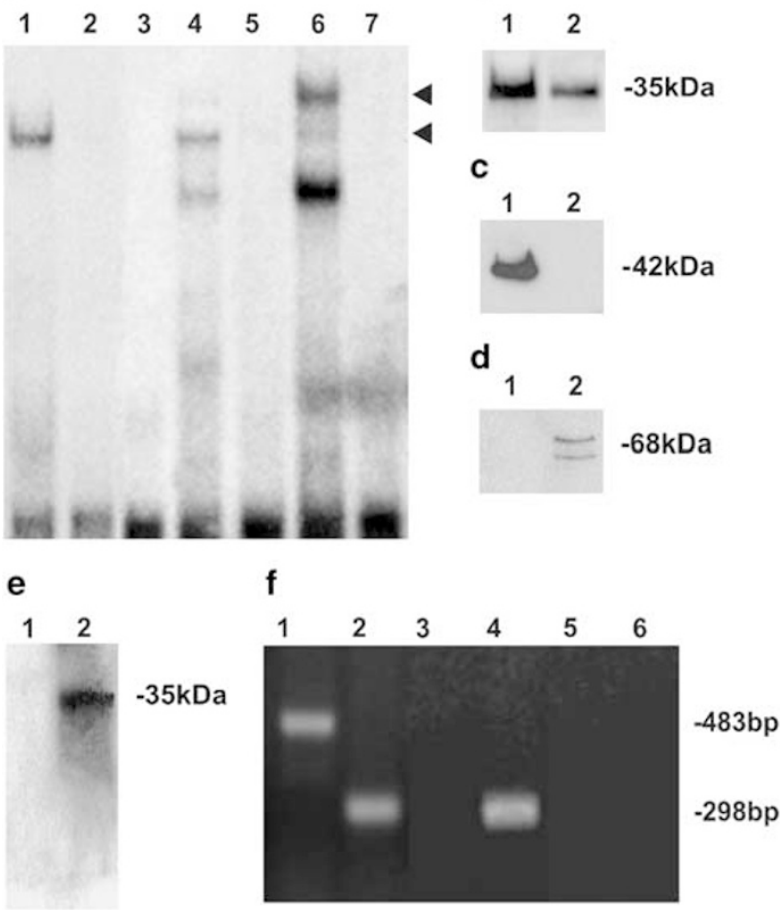

Figure 5 In vivo BUR binding of Sox2. (a) Interaction of Sox2 with the ${ }^{32} \mathrm{P}$ labeled c-myc BUR sequence in the EMSA assay. Lane 1 - in vitro translated Sox2 protein (positive control), lane 2 - in vitro translated Sox2 protein in the presence of 100 -fold excess of cold probe, lane 3 - free probe alone, lane $4-$ NT2 nuclear protein extract, lane 5 - NT2 nuclear protein extract in the presence of 100-fold excess of cold probe, lane 6 - NT2 nuclear protein extract and Sox2 antibody, lane7 - Sox2 antibody alone. Arrows indicate bands before and after the supershift with Sox2 antibody. (b-d) Western blot analysis of soluble nuclear proteins (lane 1) and nuclear matrix fraction (lane 2) extracted from NT2 cells with Sox2 antibody (b); the same blot was re-probed with $\beta$-actin antibody (c) and lamin A/C antibody (d). (e) Nuclear matrix isolates were immunoprecipitated with Sox2 antibody. Lane 1 - sample immunoprecipitaed without primary antibody, lane 2 - immunoprecipitation with Sox2 antibody. (f) Nuclear matrix isolates were immunoprecipitated with Sox2 antibody, DNA was extracted with phenol/ chloroform and PCR amplified using the primer sets spanning the c-myc BUR core sequence (298 bp, lanes 2, 4 and 6) and outside the MAR sequence (483 bp, lanes 1, 3 and 5), as described in Materials and methods. Lanes 1 and 2 - control PCR with total genomic DNA as template, lanes 3 and 4 - DNA extracted from Sox2-immunoprecipitated nuclear matrix samples, lanes 5 and 6 - DNA extracted from mock-immunoprecipitated nuclear matrix (no primary antibody)

was stripped and re-probed with antibodies for two other nuclear proteins, $\beta$-actin (Figure $5 \mathrm{c}$ ) and lamins $\mathrm{A} / \mathrm{C}$ (Figure $5 d$ ). This confirmed that the insoluble matrix contained lamins $\mathrm{A} / \mathrm{C}$ (Figure $5 \mathrm{~d}$, lane 2 ), but not $\beta$-actin, which was present only in the soluble nuclear fraction (Figure $5 c$, lane 1). These nuclear matrix isolates were subjected to immunoprecipitation protocol without and with Sox2 antibody (Figure 5e, lanes 1 and 2, respectively). DNA was extracted from the immunoprecipitated samples and PCR amplified using the same primers as in Figure 2. The results (Figure 5f, lanes 3-6) showed that the amplification of the immunoprecipitated DNA yielded only the $298 \mathrm{bp}$ fragment spanning the c-myc BUR region (lane 4), but not the 483 bp fragment outside the MAR sequence (lane 3), and no PCR product was detected in the mock-precipitated samples (lanes 5 and 6). However, both fragments were detected when total genomic DNA was used as PCR template (Figure $5 \mathrm{f}$, lanes 1 and 2). Taken together, this set of experiments established the presence of Sox2 in the nuclear matrix fraction and showed its interaction with the c-myc BUR sequence in vivo.

\section{Proteolytic degradation of SOX2 protein during apoptosis}

As shown in Figure 3, the 17-h OGD treatment triggered apoptosis in NT2 cells. We extracted nuclear proteins from these cells and examined Sox2 integrity under these conditions. As shown in Figure $6 \mathrm{~A}$, within $4 \mathrm{~h}$ after the treatment, when approximately $30 \%$ of cells were dead (Figure $3 A$ ), Sox 2 was cleaved into two fragments of 20 and $15 \mathrm{kDa}$ (lane 2). The presence of these fragments and the decreased level of intact protein were even more obvious $24 \mathrm{~h}$ after the treatment (lane 3). The kinetics of Sox2 degradation was very similar to that of PARP, a well-known apoptotic target, which also underwent site-specific proteolysis (Figure 6B). The same nuclear extracts were tested for the presence of DNA-binding activities under EMSA conditions (Figure 6C). The results showed a significantly reduced BUR-binding in the extracts from the OGD-treated cells (Figure 6C, lanes 2 and 3), and implied that the proteolysis of Sox 2 might have contributed to these changes.

The OGD-treated cells were also examined under a fluorescence microscope to examine the correlation between DNA breaks labeled by TUNEL assay and the nuclear distribution of Sox2 (Figure 6D). It was established that shortly after the OGD treatment the number of TUNELpositive cells (panels $b$, e and $h$ ) with altered nuclear morphology (panels $f$ and i) started to increase shortly after the treatment and as the cells begun to lose Sox2 signal (panels a, $d$ and g). Occasionally, the TUNEL-labeled DNA breaks were observed prior to any obvious morphological change (panels $\mathrm{a}-\mathrm{c}$ ), but the maximal TUNEL labeling was mostly seen in cells with condensed chromatin and a clear loss of Sox2 immunostaining (panels $\mathrm{d}-\mathrm{i}$ ). This phenomenon was consistent with that previously described in anti-Fastreated Jurkat cells. ${ }^{6}$

The OGD-induced apoptosis in NT2 cells was caspasedependent (Figure 7). As shown in Figure 7a, the activity of caspase-3 was nearly three-fold higher in the OGD-treated cells analyzed immediately after the treatment $(0 \mathrm{~h})$ than in controls. This increase in the proteolytic activity was blocked by the DEVD peptide inhibitor present during the assay and the presence of the inhibitor significantly reduced the percentage of trypan blue-positive cells identified, otherwise, at $3 \mathrm{~h}$ post-treatment (Figure $7 \mathrm{~b}$ ). Furthermore, the inhibition of caspase-3 activity by DEVD prevented the degradation of Sox2, as demonstrated by Western blotting (Figure 7c). Immonoblotting of the same membrane with $\beta$-actin antibody was used as a loading control (Figure 7d).

\section{Cellular distribution of Sox2}

PCR analysis showed that Sox2 was highly expressed in undifferentiated NT2 cells (Figure 8, lane 3), which upon 
A

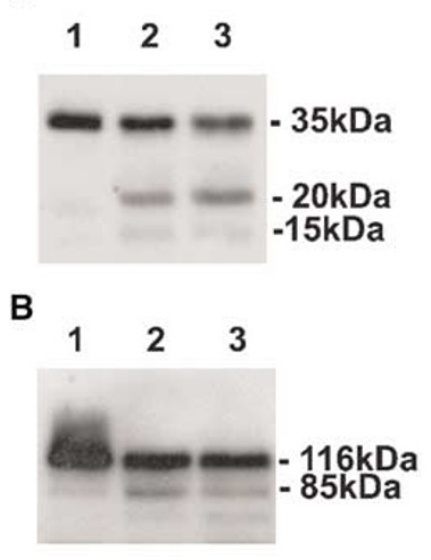

D
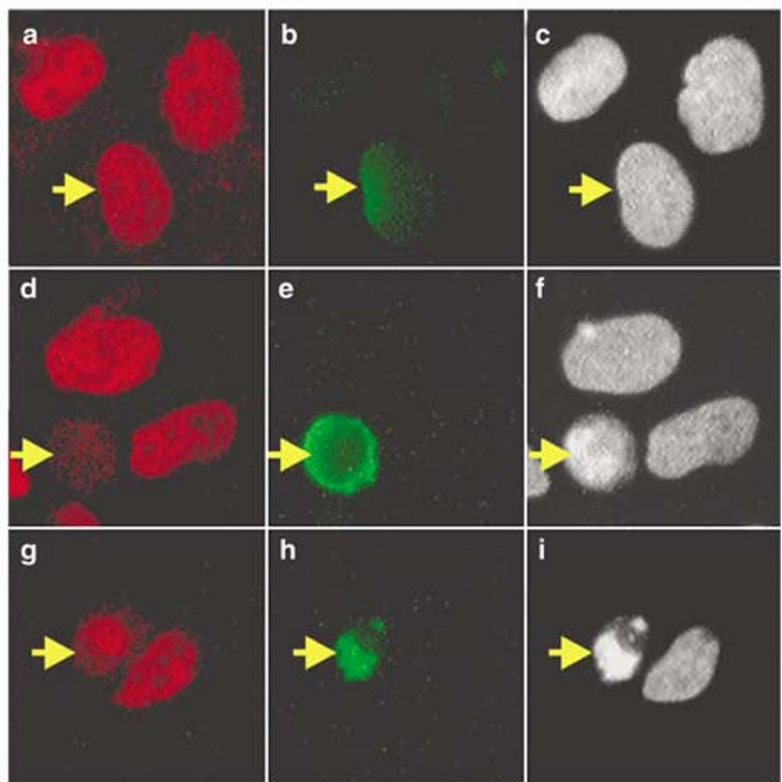

Figure 6 Alterations in the properties of Sox2 during apoptosis. (A, B) Undifferentiated NT2 cells were collected at 4 and $24 \mathrm{~h}$ after the OGD treatment. Nuclear proteins were extracted from control (lane 1) and treated cells (lanes 2 and 3) and analyzed by Western blotting with Sox2 antibody (a) and PARP antibody (b), as described in Materials and methods. (C) EMSA assay of the ${ }^{32} \mathrm{P}$ labeled c-myc BUR probe and nuclear protein extracts from apoptotic NT2 cells. Lane $\mathrm{F}$ - free probe, lane 1 - control untreated cells, lane $2-4 \mathrm{~h}$ after OGD, lane $3-24 \mathrm{~h}$ after OGD. (D) Sox2 immunostaining and TUNEL labeling of DNA breaks. NT2 cells were plated on glass coverslips, subjected to OGD and analyzed $4 \mathrm{~h}(\mathrm{a}-\mathrm{f})$ and $24 \mathrm{~h}(\mathbf{g}-\mathbf{i})$ later. The cells were fixed, stained with Sox2 antibody (a, $\mathbf{d}$ and $\mathbf{g}$ ) and labeled with terminal deoxynucleotidyl transferase using biotin-16-dUTP and CY3-conjugated streptavidin (b, e and $\mathbf{h}$ ). Nuclei were counterstained with Hoechst dye (c, $f$ and $\mathbf{i})$. The slides were examined under an Olympus B $\times 50$ fluorescence microscope. Arrows indicate TUNEL-positive cells. Images are representatives of three independent experiments

differentiation with retinoic acid (RA) give rise to neurons and astrocytes. $^{26,27}$ The transcripts were also present in human brain tissue (lane 2), NT2-derived astrocytes (lanes 5 and 6), but not in NT2-derived neurons (lane 4) and neither in a

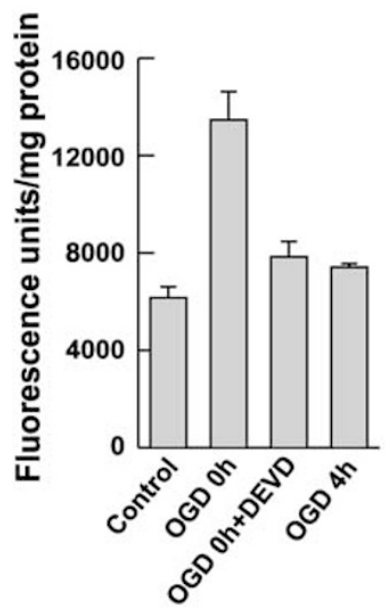

b

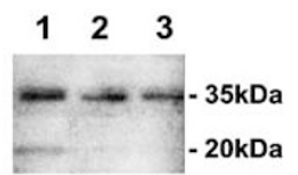

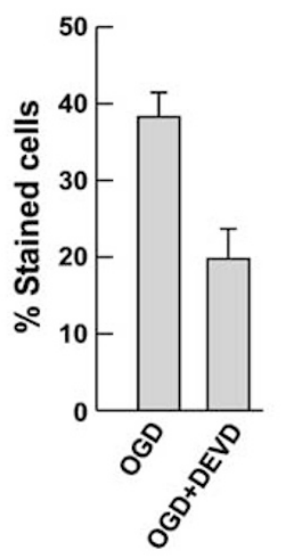

d $\quad 1 \quad 2 \quad 3$

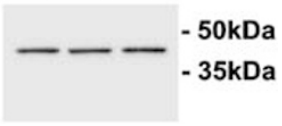

Figure 7 Cleavage of SOX2 after OGD is preceded by the activation of caspase-3. (a) Caspase-3 activity was measured in control and $17 \mathrm{~h}$ OGDtreated NT2 cells using the ApoAlert ${ }^{\mathrm{TM}}$ CPP32 Assay Kit. In some samples, $1 \mu \mathrm{M}$ DEVD was added to the cultures before placing cells in the hypoxic chamber. Bars represent the mean \pm S.E.M. data from three experiments performed in duplicate. (b) Cells were treated with OGD in the presence or absence of $1 \mu \mathrm{M}$ DEVD and cell viability was assessed $3 \mathrm{~h}$ post OGD by counting of trypan blue-labeled cells. Bars represent the mean + S.E.M. from four samples. (c, d) Cells were treated with OGD as above, protein lysates were prepared and immunoblotted with Sox2 antibody (c). The same blot was re-probed with $\beta$-actin antibody (d). Lane $1-3 \mathrm{~h}$ post-OGD, lanes 2 and $3-3 \mathrm{~h}$ post-OGD + DEVD

lymphocytic Jurkat cells (lane 7), indicating a cell-type-specific pattern of expression.

Immunofluorescence staining showed that all undifferentiated NT2 cells were Sox2-positive and the staining was exclusively nuclear (Figure $8 \mathrm{~B}, \mathrm{a}-\mathrm{c}$ ). In RA-differentiated cultures the nuclear staining of Sox 2 was evident only in large flat astrocytic cells, but not in smaller neuronal cells (Figure 8B, d-f), all consistent with the PCR data shown in Figure 8A.

The expression level of Sox2 gene during the 4-week RA treatment of NT2 cultures gradually declined to less than $40 \%$ of that measured in undifferentiated cells (Figure $8 \mathrm{C}$ ). This likely reflected its astrocytic level since these are mixed cultures containing both neurons and astrocytes ${ }^{27}$ and there was no expression of Sox 2 in pure neuronal cultures as values below $0.5 \%$ of undifferentiated cells were measured by $Q$ PCR (Figure 8E). The expression of c-myc was also detected only in undifferentiated cells (Figure 8D). The gene was turned off during RA treatment and its expression level was negligible in NT2 neurons (Figure 8F).

\section{Discussion}

MARs are thought to act as boundary elements that protect and insulate genes located between them. Moreover, MAR- 
A

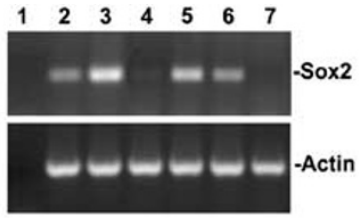

B

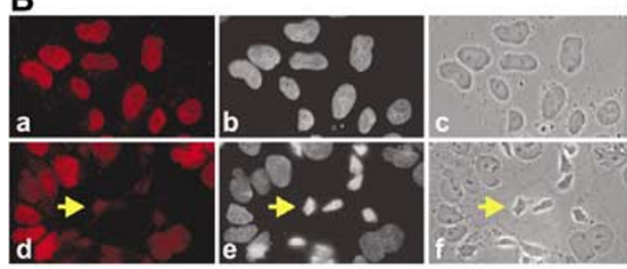

C

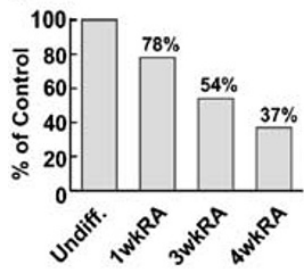

D
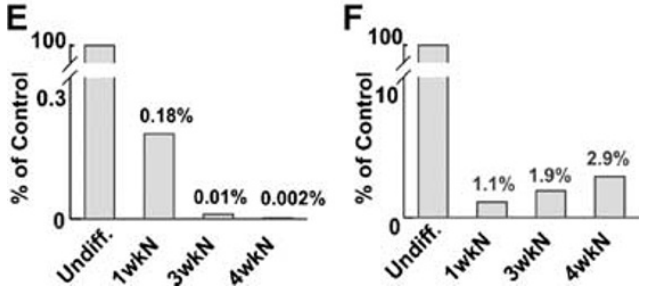

Figure 8 Expression pattern of the Sox2 gene. (A) Ethidium bromide-stained agarose gel of the Sox2 RT-PCR products (top panel) and $\beta$-actin (bottom panel). Lane 1 - negative PCR control, lane 2 - human brain sample, lane 3 undifferentiated NT2 cells, lane 4-3-week-old NT2 neuronal culture, lane 5-1week-old NT2 astrocytic culture, lane 6 - 4-week-old astrocytes, lane 7 - Jurkat cells. (B) Undifferentiated NT2 cells (a, b, c) and 3-week-old co-culture of neurons (indicated by arrow) and astrocytes (d, e and f) were grown on glass coverslips, fixed with paraformaldehyde, permeabilized and stained with Sox2 antibody (a and d). Nuclei were counterstained with Hoechst 33258 (b and e). Images, fluorescence $(\mathbf{a}, \mathbf{b}, \mathbf{d}, \mathbf{e})$ and phase contrast $(\mathbf{c}, \mathbf{f})$ were captured on an Olympus B $\times 50$-fluorescence microscope. $(\mathbf{C}-\mathbf{F})$ The expression patterns of Sox2 (C, E) and c-myc (D, F) genes were analyzed by quantitative RT-PCR during RA-induced differentiation of NT2 cells (C, D, 1wkRA-4wkRA) and neuronal maturation ( $E, F, 1 w k N-4 w k N$, 1- to 4-week-old neuronal cultures) Al samples were measured against the CDNA of undifferentiated NT2 cells (C-F undiff.) as a control. 1wkRA-4wkRA: 1-4 weeks of RA-treated NT2 cultures; 1wkN-4wkN: 1- to 4-week-old NT2 neurons

binding proteins provide a structural framework for the assembly of a DNA replication centre and transcriptional complexes. ${ }^{10,28-30}$ It has also been suggested that degradation and/or modification of MAR-binding proteins may play a key role in the molecular mechanisms of nuclear disassembly during apoptosis. ${ }^{1-4,6,15}$ Recently, using a well-characterized model of apoptosis, anti-Fas treatment of Jurkat cells, we examined the sequence integrity of several genes (the c-myc proto-oncogene, high-mobility group phosphoprotein, protamine gene cluster, pyruvate dehydrogenase alpha subunit and low-molecular-weight acid phosphatase), which all contain sequences highly similar to the $25 \mathrm{bp}$ BUR element of the $\mathrm{IgH}$ gene and known binding site of SATB1 protein. ${ }^{6}$ In all cases the DNA breaks appear in close proximity to these sites, concomitant with proteolysis of SATB1 and consistent with MARs being the initiation sites of the DNA cleavage process. However, it still remained to be answered whether these changes are specific to lymphocytic cell lines only or they represent a more general feature of apoptotic cell death, which occurs in many cell types and in response to a variety of stimuli. In the current study, we addressed this question by examining the integrity of the c-myc MAR in a different cell type and in response to a different apoptotic inducer, that is, in human neural precursor NT2 cells undergoing apoptosis in response to OGD. We have not only established the presence of ss DNA breaks in the proximity of the c-myc BUR element, but have also identified Sox2 as matrix-bound transcription factor, which was degraded in apoptotic cells, all consistent with the universal nature of this phenomenon.

The existence of a MAR within the $c$-myc gene has been known for some time; ${ }^{18,19,31}$ however, neither the core BUR element nor any binding protein that makes physical contact with the DNA has been identified. Early reports by Chou et al. ${ }^{18,19}$ indicated that the A-T-rich sequence, 5'AATTTC AATAATAGTA3', containing the first poly $(A)$ addition signal and located within the $172 \mathrm{bp}$ Dral/Dral fragment (Figure 1), is recognized by an as yet unidentified $25 \mathrm{kDa}$ (p25) nuclear protein. The authors showed sequence retention in the nuclear matrix fraction, but ruled out p25 as a MAR-binding protein. ${ }^{19}$ In the present study, we confirmed the existence of the MAR within a Clal/EcoRl fragment containing the c-myc $3^{\prime}$ UTR and demonstrated that the $22 \mathrm{bp}$ BUR-like core sequence, highly homologous to the SATB1-binding site in the $\mathrm{IgH}$ gene, was located adjacent to, but not within the 172 bp Dral/Dral fragment (Figure 1). This 22 bp sequence was clearly making physical contact with MAR-binding proteins, that is, SATB1 in Jurkat cells ${ }^{6}$ and Sox2 in NT2 cells, and, therefore, may be regarded as the true BUR element within the c-myc MAR. Binding of Sox2 to this sequence was initially identified through a yeast one-hybrid screening of a human fetal brain cDNA expression library, but it was subsequently confirmed in the EMSA assay with recombinant Sox 2 and nuclear protein extracts from NT2 cells (Figures $5 \mathrm{a}$ and $6 \mathrm{c}$ ). Furthermore, a fraction of nuclear Sox2 was tightly associated with the nuclear matrix (Figure $5 \mathrm{~b}$ ) and the c-myc MAR sequence could be immunoprecipitated with Sox2 antibody (Figure 5e and f). To our knowledge, this is the first report on the Sox2 BUR-binding properties and its specific association with the c-myc MAR.

Sox2 is a member of HMG box family of proteins that bend DNA and bind preferentially to the distorted DNA structures. They act mainly as transcriptional co-activators, but are also capable of modifying the structure of chromatin. ${ }^{32,33}$ There is also a report that HMG-I(Y), a member of this family, recognizes and binds to BURs in the matrix attachment sequences. ${ }^{14}$ Here we have provided evidence that another member of this family, Sox2, has similar BUR-binding properties. Although there is no strict consensus for the BUR core sequences in the human genome, we found that there is high degree of similarity in these sequences in a number of genes. ${ }^{6}$ Most BUR unwinding core elements consist of ATC tracts excluding G's. It is generally expected 
that mutations decreasing the BUR A-T contents abrogate their unwinding property and reduce their binding capacity to the nuclear matrix proteins. ${ }^{9,11,14}$ However, there is a unique $G$ in the ATC tract in the c-myc BUR sequence and the mutation of this $G$ to $A$ significantly decreased its interaction with Sox2 (Figure 4c), suggesting that this $G$ is important for the physical contact between DNA and Sox2. Although the number of identified Sox2 target genes is very limited, that is, $\delta$-crystallin, fibroblast growth factor 4 (FGF4) and undifferentiated embryonic cell transcription factor (1) (UTF1), their Sox2-binding sites contain the base $\mathrm{G}^{21}$ Furthermore, a recent crystal structure study of Remenyi et al. ${ }^{34}$ establishes that six out of the seven bases (CTTTGTT) of the DNA sequence in the enhancer region of FGF4 gene make physical contact with Sox2 protein. Of these, the $G$ and its complementary base $\mathrm{C}$ on the other strand make physical contact with Asn8 and Arg5 of Sox2, respectively. These six bases align well with the center of the c-myc BUR sequence, consistent with our experimental evidence showing that the cmyc MAR contains a Sox2-binding site.

The functional significance of the Sox2 interaction with the BUR core sequence located in the $3^{\prime}$ UTR of the c-myc gene is at present unknown, although it might be linked to the regulation of the activity of the gene, since there was a correlation between the levels of Sox 2 and c-myc transcripts, that is, both transcripts were high in proliferating neuronal precursors, they were downregulated during RA differentiation and Sox2 was absent from post-mitotic neurons (Figure 8). Therefore, it is possible that Sox2 function was required for the correct level of c-myc transcription in cycling cells. It is also possible that numerous Sox2-binding sites exist in the MAR regions of the genome and that this aspect of Sox2 function is required for cell-type-specific regulation of gene expression, as demonstrated for SATB1, which negatively regulates MMTV transcription in lymphoid tissues in transgenic mice. ${ }^{35}$ Further experiments are required to prove this hypothesis.

During apoptosis of NT2 cells, Sox2 protein was cleaved into two fragments, losing its MAR-binding capability, and was eliminated from the nuclei (Figure 6). This, in turn, resulted in the exposure of nuclear DNA to endonuclease digestion (Figures $3 c$ and $6 d$ ). These results are consistent with the previous studies on Jurkat cells, in which SATB1-DNA interaction decreased early in the apoptotic process due to its cleavage by caspase- 6 and the DNA within the MARs became accessible to endonucleases. ${ }^{3,6}$ The present study showed that Sox2 exhibited properties similar to SATB1 in terms of its BUR-binding propensity and sensitivity to proteolysis during OGD-induced apoptosis in NT2 cells. It is possible that Sox2 might be a functional equivalent of SATB1 in the developing CNS. However, Sox2 contains neither PDZ domain nor any obvious caspase cleavage sites and, therefore, it might not be degraded by the same mechanism. On the other hand, our data clearly showed that NT2 cells underwent caspase-dependent apoptosis, preventable by caspase inhibitor DEVD, which also blocked the degradation of Sox2 (Figure 7). This implies the involvement of an enzyme downstream of caspase-3, which was activated during the OGD treatment and prior to the proteolysis of Sox2. Although the responsible protease and precise Sox2 cleavage recognition sequence are yet to be identified, this is the first report of a
HMG box protein specific to the brain being cleaved early in apoptosis. A correctly executed apoptotic process is essential to the development of CNS. It occurs during the closure of neural tube, ${ }^{36}$ during the development of mesencephalic region $^{20}$ and during corticogenesis, ${ }^{37}$ and it is the balance between two genetically controlled processes, proliferation and apoptosis, that ensures the correct cell number in the developing CNS. ${ }^{38}$

In conclusion, many nuclear DNA-binding proteins, whether they are transcription factors like Sox2, DNA repair enzymes like topoisomerase II and PARP, or nuclear matrix proteins like SATB1, undergo proteolysis during the process of apoptosis. Their binding sites conceivably lie within the unpaired regions of nuclear DNA, especially since some of them preferentially bind distorted or bent DNA, leaving these sites vulnerable. This occurs in different cell types and in response to different inducers, likely as a component of the molecular mechanisms of apoptotic cell death.

\section{Materials and Methods}

\section{Cell culture}

Human acute T-cell leukemia Jurkat cells (ATCC T1B152) and human embryonal carcinoma NT2 cells (Stratagene, La Jolla, CA, USA) were cultured in RPMI 1640 medium and high-glucose DMEM (Invitrogen Life Technologies, Burlington, ON, Canada), respectively. Both cultures were supplemented with $10 \%$ fetal bovine serum (FBS; Wisent Inc., St. Bruno, $\mathrm{QC}$, Canada) and were incubated at $37^{\circ} \mathrm{C}$ in a $5 \% \mathrm{CO}_{2}$ atmosphere. NT2 cells were differentiated into neurons and astrocytes with all trans-retinoic acid (RA, Sigma, Oakville, ON, Canada) according to the method of Pleasure and Lee, ${ }^{26}$ as described previously. ${ }^{39}$

\section{OGD treatment}

NT2 cells in T25 flasks (70\% confluent) were washed once with glucosefree DMEM, and incubated in glucose-free DMEM with $10 \% \mathrm{FBS}$ for $17 \mathrm{~h}$ in a Gas Pak 100 chamber (VWR, Montreal, QC, Canada) as described previously. ${ }^{40}$ At the end of the OGD treatment (designated $0 \mathrm{~h}$ ), cells were removed from the chamber and returned to the incubator for 3,4 or $24 \mathrm{~h}$. Cell viability was assessed by the Trypan Blue exclusion assay. Labeled cells were counted using a hemocytometer.

\section{Caspase activity assay}

NT2 cells grown in T25 flasks were treated with OGD for $17 \mathrm{~h}$, pelleted, and caspase-3 activity was measured using the ApoAlert ${ }^{\mathrm{TM}}$ CPP32 Assay Kit (Clonetech laboratories Inc., Palo Alto, CA, USA) as described previously. ${ }^{41}$ Control cells were grown under normal culture conditions in the presence of glucose. In some samples, $1 \mu \mathrm{M}$ DEVD (caspase-3 inhibitor) was added to the cultures before placing cells in the hypoxic chamber.

\section{Isolation of nuclei and nuclear matrix}

NT2 cells $\left(2 \times 10^{7} /\right.$ sample) were washed with PBS $(137 \mathrm{mM} \mathrm{NaCl}$, $2.7 \mathrm{mM} \mathrm{KCl}, 4.3 \mathrm{mM} \mathrm{Na}_{2} \mathrm{HPO}_{4}$ and $1.4 \mathrm{mM} \mathrm{KH}_{2} \mathrm{PO}_{4}$ ), centrifuged at $194 \times g$ for $5 \mathrm{~min}$ and lysed in $4 \mathrm{ml} \mathrm{NP40}$ buffer (10 mM Tris, pH 7.4, $\left.10 \mathrm{mM} \mathrm{NaCl}, 3 \mathrm{mM} \mathrm{MgCl}_{2}, 0.5 \% \mathrm{NP} 40(\mathrm{v} / \mathrm{v})\right)$ on ice for $5 \mathrm{~min}$. Nuclei were collected by centrifugation as above. The nuclear matrix was isolated using a procedure adopted from Gasser and Laemmli. ${ }^{42}$ Nuclei were 
resuspended in $100 \mu$ l of nuclear lysis buffer ( $5 \mathrm{mM}$ Tris, $\mathrm{pH} 7.4,20 \mathrm{mM}$ $\mathrm{KCl}, 0.125 \mathrm{mM}$ spermidine, $0.05 \mathrm{mM}$ spermine, $0.1 \%$ digitonin, $1 \%$ thiodiglycol, $0.1 \mathrm{mM}$ phenylmethylsulfonyl fluoride and $1 \times$ protease inhibitor cocktail, Roche Diagnostics, Laval, QC, Canada), incubated at $37^{\circ} \mathrm{C}$ for $20 \mathrm{~min}$, then extracted on ice for $10 \mathrm{~min}$ in $4 \mathrm{ml}$ of LIS buffer (25 mM 3,5-diiodosalicylic acid, lithium salt, 5 mM Hepes, pH 7.4, 0.25 mM spermidine, $2 \mathrm{mM} \mathrm{KCl}, 2 \mathrm{mM}$ EDTA, $0.1 \%$ digitonin). The nuclear matrix was collected by centrifugation at $2400 \times g$ for $20 \mathrm{~min}$ at $4^{\circ} \mathrm{C}$ and was washed four times with NEBuffer 4 (New England Biolabs, Mississauga, ON, Canada).

\section{Sacl and Hincll digestion}

One-third of the matrix preparation and $10 \mu \mathrm{g}$ of genomic DNA, isolated according to the method of Ausubel et al., ${ }^{43}$ were double digested separately with Sacl and Hincll $\left(1000 \mathrm{u} / \mathrm{ml}\right.$ each) overnight at $37^{\circ} \mathrm{C}$. Digestion was stopped by heating at $65^{\circ} \mathrm{C}$ for $20 \mathrm{~min}$. The matrix samples were diluted to a half of the original extraction volume with NEBuffer 4 and re-pelleted at $2400 \times g$ for $10 \mathrm{~min}$. The matrix pellets were washed three times and resuspended in $340 \mu$ l of TE buffer ( $10 \mathrm{mM}$ Tris, $\mathrm{pH} 7.5,1 \mathrm{mM}$ EDTA). The genomic DNA samples were processed the same way. The samples were incubated for $4 \mathrm{~h}$ at $37^{\circ} \mathrm{C}$ with $1 \mathrm{mg} / \mathrm{ml}$ Proteinase $\mathrm{K}$ and $1 \%$ sodium dodecyl sulfate. The DNA was purified by phenol/chloroform extraction, precipitated with ethanol and dissolved in $35 \mu \mathrm{l}$ of TE buffer. The DNA samples were used for subsequent PCR analysis.

\section{Immunoprecipitation of nuclear matrix}

Nuclear matrix pellets isolated from $2 \times 10^{7}$ cells (after restriction digestion, but prior to phenol chloroform extraction) were resuspended in $100 \mu$ l of Co-ip buffer (20 mM Tris, pH 7.5, $150 \mathrm{mM} \mathrm{NaCl}, 1 \times$ protease inhibitor cocktail, $0.1 \%$ Tween-20, 0.1\% BSA). Immunoprecipitation was carried out as described by Liu et al. ${ }^{44}$ using $5 \mu$ of rabbit polyclonal Sox2 antibody (prepared as described below) and $2 \mu$ l biotin-conjugated rabbit secondary antibody (Jackson ImmunoResearch, West Grove, PA, USA). A mock reaction without primary antibody was run in parallel as a control. The bead-bound complexes were boiled for $5 \mathrm{~min}$ in TE buffer with $10 \%$ SDS and the supernatant was collected using the supplied magnetic stand. Proteinase $\mathrm{K}$ digestion and phenol chloroform extraction were carried out as described above. The final DNA pellet was dissolved in $10 \mu \mathrm{l}$ TE buffer and the samples were used for PCR analysis.

\section{PCR analysis of immunoprecipitated DNA}

In all, $4 \mu$ l of matrix-extracted DNA or $2 \mu$ l of total genomic DNA in a $20 \mu \mathrm{l}$ reaction mixture was analyzed by PCR using primers $L P 1-5^{\prime}$ TGTTT CT CTGTAAATAT TGCCATT $3^{\prime}$ and RP1 - 5' GAAGGGGCAATTGATGAAA A $3^{\prime}$, amplifying a $298 \mathrm{bp}$ fragment spanning the BUR-like sequence, or LP2 - 5' CTGGGAAGAAGCCAGTTCAG $3^{\prime}$ and RP2 - 5' GGATTGCATC TCCCTTTG AA $3^{\prime}$, amplifying a 483 bp region outside the BUR-like sequence (Figure 1). PCR was performed as follows: one cycle at $94^{\circ} \mathrm{C}$ for $5 \mathrm{~min}, 25$ cycles of $94 \times \mathrm{C}$ for $45 \mathrm{~s}, 60^{\circ} \mathrm{C}$ for $45 \mathrm{~s}$ and $72^{\circ} \mathrm{C}$ for $45 \mathrm{~s}$. In the last cycle, the incubation was extended for $5 \mathrm{~min}$ at $72^{\circ} \mathrm{C}$ The samples were separated on a $1 \%$ agarose gel containing $0.5 \mu \mathrm{g} / \mathrm{ml}$ ethidium bromide and photographed.

\section{Ligation-mediated PCR (LMPCR) analysis}

LMPCR analysis of genomic DNA extracted from control and OGD-treated NT2 cells was performed according to the modified protocol of Ausubel et al., ${ }^{43}$ as previously described by Liu et al. ${ }^{6,43}$ Briefly, c-myc genespecific primers (Figure 1, Table 1) were used to detect single-strand breaks in the genomic DNA. The assay was performed using $2 \mu \mathrm{g}$ of restriction-digested (Xhol, Bgh/ll) genomic DNA per sample. The first LMP1 primer was extended with Vent DNA polymerase. The doublestranded blunt-end DNA was then ligated with a staggered linker DNA. In all, 18 cycles of PCR were completed after adding LMP2 and linker primers to the reaction and the final PCR cycle was carried out by adding a ${ }^{32} \mathrm{P}$-labeled LMP3 primer into the reaction. The radiolabeled PCR products were visualized on a polyacrylamide DNA-sequencing gel.

\section{Yeast one-hybrid screening and the characterization of the isolated cDNA clone}

Double-stranded reporter DNA sequences were produced by annealing the following two oligonucleotides: $5^{\prime}$ AATTC(EcoRI)TTTTTTCTATTGTTT TTAGAATTTTTTCTATTGTTTTTAGAATTTTTTCTATTGTTTTTAGAATTT TTTCTATTGTTTTTTAGAAA (/G) 3' and 5' CGCGT(/TCGAC)(Mlul/Sall)TT CTAAAAACAATAGAAAAAATTCTAAAAACAATAGAAAAAATTCTAAAAA CAATAGAAAAAATTCTAAAAACAATAGAAAAAAG $3^{\prime}$, representing the sense and antisense strands of four tandem copies of the c-myc BUR-like core sequence. The reporter sequences were then cloned into EcoRI/Mlul and EcoRI/Sall sites of pHISi and pLacZi vectors and subsequently integrated into Saccharomyces cerevisiae YM4271 cells to generate reporter strains, YM4271::Myc::His3 and YM4271::Myc::LacZ. For library screening, the reporter strain YM4271::Myc:: His3 was transformed with a pACT2 human fetal brain cDNA library (Clotech, Palo Alto, CA, USA) using the LiAc/polyethylene glycol method. The screening of DNAprotein interaction was performed using SD/-His-Leu synthetic medium with $45 \mathrm{mM} 3$-aminotriazole, a competitive inhibitor of the yeast HIS3 protein. Library plasmids were recovered from the $\mathrm{His}{ }^{+}$clones and tested for the activation of the LacZ reporter gene in the YM4271:: Myc::LacZ strain using filter assay. ${ }^{43}$ Cells containing the plasmid were streaked on $\mathrm{SD} /$-Ura-Leu plate and incubated at $30^{\circ} \mathrm{C}$ overnight. Colonies were lifted with a nylon membrane which was dried at room temperature for $5 \mathrm{~min}$, chilled twice at $-70^{\circ} \mathrm{C}$ for $10 \mathrm{~min}$, incubated at $30^{\circ} \mathrm{C}$ on Whatman $3 \mathrm{MM}$ paper soaked in Z buffer with $1 \mathrm{mg} / \mathrm{ml}$ X-gal (Sigma, Oakville, ON, Canada), and photographed. All vectors, yeast strains and the human cDNA library were purchased from Clontech, Palo Alto, CA, USA. His ${ }^{+}$and $\mathrm{LacZ}^{+}$-positive clones were sequenced for GenBank searches and analysis.

\section{In vitro transcription/translation of Sox2 protein}

The coding region of Sox2 cDNA was amplified from isolated Sox2 clones using $5^{\prime}$ TCTCTCGGTACCATGTACAACATG ATGGAGACG $3^{\prime}$ and $5^{\prime}$ AAGTGAACTTGCGGGGTTTTTCAGTATCTACG $3^{\prime}$ as forward and reverse primers. The amplified Sox2 cDNA fragment was inserted into

Table 1 PCR and LM-PCR primers illustrated in Figure 1

\begin{tabular}{llr}
\hline $\begin{array}{l}\text { Primer } \\
\text { name }\end{array}$ & \multicolumn{1}{c}{ Pequence } & \\
\hline LP1 & $5^{\prime}$ TGTTT CTCTGTAAATAT TGCCATT 3' & $7471-7494$ \\
RP1 & $5^{\prime}$ GAAGGGGCAATTGATGAAAA 3' & $7749-7768$ \\
LP2 & $5^{\prime}$ CTGGGAAGAAGCCAGTTCAG 3' & $8859-8878$ \\
RP2 & $5^{\prime}$ GGATTGCATCTCCCTTTGAA 3' & $9322-9341$ \\
LMP1 & $5^{\prime}$ ATGCTTAGGAGTGCTTGGGAC 3' & $8425-8445$ \\
LMP2 & $5^{\prime}$ TCCTTTGCCTACCTCTCACCTTCTC 3' & $7921-7945$ \\
LMP3 & $5^{\prime}$ TCCTTTGCCTACCTCTCACCTTCTCACC $3^{\prime}$ & $7918-7945$
\end{tabular}


the Kpnl/Xhol sites of pcDNA3 vector (Invitrogen, Burlington, ON, Canada) for in vitro transcription and translation using a TNT T7-coupled reticulocyte lysate system (Promega, Madison, WI, USA).

\section{RT-PCR analysis of SOX2 expression}

Total RNA was extracted from Jurkat and NT2 cells using the Tri-reagent method (MRC Inc., Cincinnati, OH, USA). Trace DNA contamination was removed using the DNA-free kit (Ambion Inc., Austin, TX, USA). Total RNA was reverse transcribed and CDNA was purified and quantified as described by Fang et al. ${ }^{40} \mathrm{~A} 220$ bp cDNA fragment of Sox2 was amplified from $200 \mathrm{ng}$ of template DNA using high-fidelity Taq polymerase (Clontech, Palo Alto, CA, USA) with the following primers: Sox2F: $5^{\prime}$ ATGTACAAC ATGAT GGAGA CG $3^{\prime}$ and SOX2R: $5^{\prime}$ GCGCTTGCTGAT CTCCGAGT $3^{\prime}$. PCR conditions were: one cycle at $94^{\circ} \mathrm{C}$ for $5 \mathrm{~min}, 30$ cycles for $1 \mathrm{~min}$ at $94^{\circ} \mathrm{C}, 1 \mathrm{~min}$ at $60^{\circ} \mathrm{C}$ and $1 \mathrm{~min}$ at $72^{\circ} \mathrm{C}$, and one cycle at $72^{\circ} \mathrm{C}$ for $5 \mathrm{~min}$. The product was separated on a $1 \%$ agarose gel containing $0.5 \mu \mathrm{g} / \mathrm{ml}$ ethidium bromide and photographed.

\section{Electrophoretic mobility shift assay (EMSA)}

Double-stranded BUR-like sequence was generated by annealing the two complementary strands $5^{\prime}$ TTTTTTCTATTGTTTTTAGAA $3^{\prime}$ to $5^{\prime}$ TTCTAA AAAC AATAG AAAAAA $3^{\prime}$ of oligonucleotides. The probe was prepared by labeling the DNA ends with Klenow DNA polymerase (USB) and ${ }^{32}$ P-dATP. Protein-DNA complexes were formed by incubating 50,000 $60,000 \mathrm{cpm}$ of ${ }^{32} \mathrm{P}$-labeled probe with $0.25-0.5 \mu \mathrm{l}$ of in vitro translated Sox2 protein or $2-5 \mu \mathrm{g}$ of nuclear protein extracted using the method described by Testolin et al..$^{45}$ In the competition assays, a 100-fold excess of unlabeled probe was added to the reaction mixture $30 \mathrm{~min}$ prior to the addition of the labeled oligonucleotides. In the antibody supershift assays, reaction mixtures were pre-incubated for $30 \mathrm{~min}$ at room temperature with $1 \mu \mathrm{l}$ of rabbit polyclonal anti-Sox2 antibody generated as described below. DNA-protein complexes were resolved by electrophoresis on a nondenaturing $6 \%$ polyacrylamide gel run in $50 \mathrm{mM}$ Tris, $1 \mathrm{mM}$ EDTA and $300 \mathrm{mM}$ glycine buffer ( $\mathrm{pH} 8.6-8.7)$, and were visualized by autoradiography on Kodak BioMax MS film.

\section{Generation of Sox2 polyclonal antibody}

CDNA for the human Sox2 gene containing the entire coding region was cloned into $\mathrm{pBAD} / \mathrm{His} \mathrm{A}$ vector (Invitrogen, Burlington, ON, Canada) according to the manufacturer's instructions. The His-tagged Sox2 fusion protein was expressed, extracted from Escherichia coli strain LMG 194, and purified using a His-Trip nickel column (Pharmacia Biotech, Baie d' urfe', QC, Canada). The protein sample was lyophilized and reconstituted in PBS $\left(137 \mathrm{mM} \mathrm{NaCl}, 2.7 \mathrm{mM} \mathrm{KCl}, 4.3 \mathrm{mM} \mathrm{Na} \mathrm{HPO}_{4}\right.$ and $1.4 \mathrm{mM}$ $\mathrm{KH}_{2} \mathrm{PO}_{4}$ ). White male New Zealand rabbits were immunized once with $500 \mu \mathrm{g}$ of protein, then three times with $250 \mu \mathrm{g}$ protein within a 4-week interval. Polyclonal anti-Sox2 antibody was collected 14 days after the last booster shot.

\section{Immunostaining and Western blot analysis}

Immunofluorescence staining was performed as described previously ${ }^{46}$ using anti-Sox2 antibody at $1: 250$, followed by rhodamine-conjugated anti-rabbit secondary antibody at 1:500. DNA breaks were detected by TUNEL as described by Gavrieli et al. ${ }^{47}$ using biotin-16-dUTP (Boehringer Mannheim, Laval, QC, Canada) visualized with ALEXA-conjugated streptavidin. Nuclear proteins were extracted as in Testolin et al. ${ }^{45}$
Nuclear proteins $(50 \mu \mathrm{g} /$ lane) were separated by $10 \%$ SDS-PAGE and electrotransferred onto a nitrocellulose membrane, as described previously. ${ }^{46}$ The following primary antibodies were used: anti-Sox2 (1:10000), mouse monoclonal anti-PARP $(1: 5000$, courtesy of Dr. G Poirier, Faculty of Medicine, Laval University, QC, Canada), rabbit polyclonal anti-lamin A/C (1: 1000, IMGENEX, San Diego, CA, USA) and mouse monoclonal anti-actin (1: 1000, ICN, Fisher Scientific, Ottawa, ON, Canada). The antigens were detected by HRP-conjugated secondary antibodies anti-rabbit $(1: 3000)$ and anti-mouse $(1: 3000)$, respectively. All secondary antibodies and ALEXA-streptavidin were purchased from Jackson ImmunoResearch Laboratories, Inc. Antibody-antigen complexes were detected by ECL (Amersham Pharmacia Biotech, Baie d' urfe', QC, Canada) using an X-ray film (Kodak BioMax MS film).

\section{Acknowledgements}

We are grateful to Dr. Jagdeep Sandhu, Ms. Dao Ly and Ms. Kirsty A Malone for providing RNA samples of NT2 cells.

\section{References}

1. Walker PR and Sikorska M (1997) New aspects of the mechanism of DNA fragmentation in apoptosis. Biochem. Cell Biol. 75: 287-299

2. Walker PR, LeBlanc J and Sikorska M (1997) Evidence that DNA fragmentation in apoptosis is initiated and propagated by single-strand breaks. Cell Death Differ. 4: 506-515

3. Galande S, Dickinson LA, Mian IS, Sikorska M and Kohwi-Shigematsu T (2001) SATB1 cleavage by caspase 6 disrupts PDZ domain-mediated dimerization, causing detachment from chromatin early in T-cell apoptosis. Mol. Cell. Biol. 21: $5591-5604$

4. Gohring F, Schwab BL, Nicotera P, Leist M and Fackelmayer FO (1997) The novel SAR-binding domain of scaffold attachment factor A (SAF-A) is a target in apoptotic nuclear breakdown. EMBO J. 16: 7361-7371

5. Khodarev NN, Bennett T, Shearing N, Sokolova I, Koudelik J, Walter S, Villalobos M and Vaughan AT (2000) LINE L1 retrotransposable element is targeted during the initial stages of apoptotic DNA fragmentation. J. Cell. Biochem. 79: 486-495

6. Liu QY, Ribecco-Lutkiewicz M, Carson C, Testolin L, Bergeron D, KohwiShigematsu T, Walker PR and Sikorska M (2003) Mapping the initial DNA breaks in apoptotic Jurkat cells using ligation-mediated PCR. Cell Death Differ. 10: $278-289$

7. Nelson WG, Pienta KJ, Barrack ER and Coffey DS (1986) The role of the nuclear matrix in the organization and function of DNA. Annu. Rev. Biophys. Biophys. Chem. 15: 457-475

8. Liebich I, Bode J, Frisch M and Wingender E (2002) S/MARt DB: a database on scaffold/matrix attached regions. Nucleic Acids Res. 30: 372-374

9. Kohwi-Shigematsu T and Kohwi Y (1990) Torsional stress stabilizes extended base unpairing in suppressor sites flanking immunoglobulin heavy chain enhancer. Biochemistry 29: 9551-9560

10. Kohwi-Shigematsu T, Maass K and Bode J (1997) A thymocyte factor SATB1 suppresses transcription of stably integrated matrix-attachment region-linked reporter genes. Biochemistry 36: 12005-12010

11. Dickinson LA, Joh T, Kohwi Y and Kohwi-Shigematsu T (1992) A tissue-specific MAR/SAR DNA-binding protein with unusual binding site recognition. Cell 70 : 631-645

12. Galande $S$ and Kohwi-Shigematsu T (1999) Poly(ADP-ribose) polymerase and $\mathrm{Ku}$ autoantigen form a complex and synergistically bind to matrix attachment sequences. J. Biol. Chem. 274: 20521-20528

13. Herrscher RF, Kaplan MH, Lelsz DL, Das C, Scheuermann R and Tucker PW (1995) The immunoglobulin heavy-chain matrix-associating regions are bound by Bright: a B cell-specific trans-activator that describes a new DNA-binding protein family. Genes Dev. 9: 3067-3082

14. Liu WM, Guerra-Vladusic FK, Kurakata S, Lupu R and Kohwi-Shigematsu T (1999) HMG-I(Y) recognizes base-unpairing regions of matrix attachment 
sequences and its increased expression is directly linked to metastatic breast cancer phenotype. Cancer Res. 59: 5695-5703

15. Martelli AM, Bareggi R, Bortul R, Grill V, Narducci P and Zweyer M (1997) The nuclear matrix and apoptosis. Histochem. Cell. Biol. 108: 1-10

16. Gotzmann J, Meissner M and Gerner C (2000) The fate of the nuclear matrixassociated-region-binding protein SATB1 during apoptosis. Cell Death Differ. 7: $425-438$

17. Kipp M, Schwab BL, Przybylski M, Nicotera P and Fackelmayer FO (2000) Apoptotic cleavage of scaffold attachment factor A (SAF-A) by caspase-3 occurs at a noncanonical cleavage site. J. Biol. Chem. 275: 5031-5036

18. Chou RH, Churchill JR, Flubacher MM, Mapstone DE and Jones J (1990) Identification of a nuclear matrix-associated region of the c-myc protooncogene and its recognition by a nuclear protein in the human leukemia HL-60 cell line. Cancer Res. 50: 3199-3206

19. Chou RH, Churchill JR, Mapstone DE and Flubacher MM (1991) Sequencespecific binding of a c-myc nuclear-matrix-associated region shows increased nuclear matrix retention after leukemic cell $(\mathrm{HL}-60)$ differentiation. Am. J. Anat. 191: 312-320

20. Graham V, Khudyakov J, Ellis P and Pevny L (2003) SOX2 functions to maintain neural progenitor identity. Neuron 39: 749-765

21. Kamachi $Y$, Uchikawa $M$ and Kondoh $H(2000)$ Pairing SOX off: with partners in the regulation of embryonic development. Trends Genet. 16: 182-187

22. Pevny LH and Lovell-Badge R (1997) Sox genes find their feet. Curr. Opin. Genet. Dev. 7: 338-344

23. Wegner M (1999) From head to toes: the multiple facets of Sox proteins Nucleic Acids Res. 27: 1409-1420

24. Frisch M, Frech K, Klingenhoff A, Cartharius K, Liebich I and Werner T (2002) In silico prediction of scaffold/matrix attachment regions in large genomic sequences. Genome Res. 12: 349-354

25. Kent WJ, Sugnet CW, Furey TS, Roskin KM, Pringle TH, Zahler AM and Haussler D (2002) The human genome browser at UCSC. Genome Res. 12: 996-1006

26. Pleasure SJ and Lee VM (1993) NTera 2 cells: a human cell line which displays characteristics expected of a human committed neuronal progenitor cell. J. Neurosci. Res. 35: 585-602

27. Sandhu JK, Sikorska M and Walker PR (2002) Characterization of astrocytes derived from human NTera-2/D1 embryonal carcinoma cells. J. Neurosci. Res. 68: 604-614

28. Bode J, Stengert-Iber M, Kay V, Schlake T and Dietz-Pfeilstetter A (1996) Scaffold/matrix-attached regions: topological switches with multiple regulatory functions. Crit. Rev. Eukaryot. Gene Expr. 6: 115-138

29. Bode J, Goetze S, Heng H, Krawetz SA and Benham C (2003) From DNA structure to gene expression: mediators of nuclear compartmentalization and dynamics. Chromosome Res. 11: 435-445

30. Khodarev NN, Sokolova IA and Vaughan AT (1998) Association between DNA cleavage during apoptosis and regions of chromatin replication. J. Cell. Biochem. 70: 604-615

31. Lauber AH, Barrett TJ, Subramaniam M, Schuchard $M$ and Spelsberg TC (1997) A DNA-binding element for a steroid receptor-binding factor is flanked by dual nuclear matrix DNA attachment sites in the c-myc gene promoter. J. Biol. Chem. 272: 24657-24665

32. Scaffidi $P$ and Bianchi ME (2001) Spatially precise DNA bending is an essential activity of the sox2 transcription factor. J. Biol. Chem. 276: 47296-47302

33. Thomas JO and Travers AA (2001) HMG1 and 2, and related 'architectural' DNA-binding proteins. Trends Biochem. Sci. 26: 167-174

34. Remenyi A, Lins K, Nissen LJ, Reinbold R, Scholer HR and Wilmanns M (2003) Crystal structure of a POU/HMG/DNA ternary complex suggests differential assembly of Oct4 and Sox2 on two enhancers. Genes Dev. 17: 2048-2059

35. Liu J, Bramblett D, Zhu Q, Lozano M, Kobayashi R, Ross SR and Dudley JP (1997) The matrix attachment region-binding protein SATB1 participates in negative regulation of tissue-specific gene expression. Mol. Cell. Biol. 17: 5275-5287

36. Geelen JA and Langman J (1977) Closure of the neural tube in the cephalic region of the mouse embryo. Anat. Rec. 189: 625-640

37. Simonati A, Tosati C, Rosso T, Piazzola E and Rizzuto N (1999) Cell proliferation and death: morphological evidence during corticogenesis in the developing human brain. Microsc. Res. Tech. 45: 341-352

38. Chan WY, Lorke DE, Tiu SC and Yew DT (2002) Proliferation and apoptosis in the developing human neocortex. Anat. Rec. 267: 261-276

39. Sodja C, Fang H, Dasgupta T, Ribecco M, Walker PR and Sikorska M (2002) Identification of functional dopamine receptors in human teratocarcinoma NT2 cells. Brain Res. Mol. Brain Res. 99: 83-91

40. Fang H, Chartier J, Sodja C, Desbois A, Ribecco-Lutkiewicz M, Walker PR and Sikorska M (2003) Transcriptional activation of the human brain-derived neurotrophic factor gene promoter. J. Biol. Chem. 278: 26401-26409

41. Liu QY, Carson C, Ribecco M, Testolin L, Raptis L, Walker PR and Sikorska M (2000) Effects of neoplastic transformation and teniposide (VM26) on protein kinase $\mathrm{C}$ isoform expression in rodent fibroblasts. Cancer Lett. 153: 13-23

42. Gasser SM and Laemmli UK (1986) Cohabitation of scaffold binding regions with upstream/enhancer elements of three developmentally regulated genes of D. melanogaster. Cell 46: 521-530

43. Ausubel FM, Brent R, Kingston RE, Moore DD, Smith JA, Seidman JG and Struhl K (1987) Current Protocols in Molecular Biology New York: J. Wiley and Sons, Inc.

44. Liu QY, Lei JX, LeBlanc J, Sodja C, Ly D, Charlebois C, Walker PR, Yamada T, Hirohashi S and Sikorska M (2004) Regulation of DNaseY activity by actininalpha4 during apoptosis. Cell Death Differ. 11: 645-654

45. Testolin L, Carson C, Wang Y, Walker PR, Armato U and Sikorska M (1997) Jun and JNK kinase are activated in thymocytes in response to VM26 and radiation but not glucocorticoids. Exp. Cell. Res. 230: 220-232

46. Liu QY, Pandey S, Singh RK, Lin W, Ribecco M, Borowy-Borowski H, Smith B, LeBlanc J, Walker PR and Sikorska M (1998) DNaseY: a rat DNasel-like gene coding for a constitutively expressed chromatin-bound endonuclease. Biochemistry 37: 10134-10143

47. Gavrieli $Y$, Sherman $Y$ and Ben Sasson SA (1992) Identification of programmed cell death in situ via specific labeling of nuclear DNA fragmentation. J. Cell. Biol. 119: 493-501 